Peer-Reviewed Article

ISSN: 2162-3104 Print/ ISSN: 2166-3750 Online

Volume 6, Issue 2 (2016), pp. 501-526

(C) Journal of International Students

http://jistudents.org/

\title{
Challenges for Global Learners: A Qualitative Study of the Concerns and Difficulties of International Students
}

\author{
Chetanath Gautam \\ Stephen F. Austin State University (USA) \\ Charles L. Lowery \\ Ohio University (USA) \\ Chance Mays \\ Mt. Enterprise High School (USA) \\ Dayan Durant \\ Stephen F. Austin State University (USA)
}

\begin{abstract}
The authors in this study seek to inform academia about international students' experiences and challenges while attending universities in Small Town USA. Despite their eagerness to study in the United States (U.S.), international students are faced with setbacks that many universities fail to recognize or realize. The researchers conducted indepth interviews with a purposive sample of students using questions based on information from the literature and an initial survey. The themes that emerged from the data analysis were language, jobs/finances, transportation, assimilation, religious interactions, and identity. Findings emphasize the imperative to understand the challenges these students face as they continue their educational journeys in the United States.


Keywords: global learners, higher education, identity, international studies, language

According to the Institute of International Education (IIE, 2013) there are 819,644 international students studying in the U.S. IIE (2013) further provides data that the top ten countries from which these students come are China, India, South Korea, Saudi Arabia, Canada, Taiwan, Japan, Vietnam, Mexico, and Turkey. The top five programs in which these students engage are Business and Management, Engineering, Math and Computer Science, Social Sciences, and Physical and Life Sciences. In the fiscal year 2012-2013, international students contributed $\$ 24.7$ billion to the U.S. economy through tuition and other living expenses (as cited in IIE, 2013).

There are many relevant accounts that praise the contributions of the international student population in the United States. According to Levin (2008), about half of the U.S. Nobel Prize winners were foreign-born U.S. citizens. Similarly, U.S. research universities attracted the most outstanding students from around the world (Levin, 2008). These international students either remained in the United States or returned to their home country. As Levin (2008) pointed out, "If foreign graduates stay, they strengthen the productive capacity of the U.S. economy. If they go home, they increase the capacity of their home economies, but they also serve as ambassadors for openness, freedom of expression, and democracy" (p. 2). This benefits both counties in this relationship.

A college education in the United States (U.S.) is arguably one of the best in the world (Hazelkorn, 2011). As such, the U.S. is possibly one of the world's most attractive destinations for international students wanting to capitalize on a first-class tertiary university education. According to the International Students Institute, international students make up $4 \%$ of the total U.S. higher education population with $38 \%$ being graduate students, $41 \%$ undergraduate, $9 \%$ non-degree and $12 \%$ having graduated and pursuing optional practical training (International Educational Exchange, 2013). Notwithstanding the challenges and barriers to entry that comprise obtaining an F-1 or J-1 student visa prior to coming to the United States (Department of Homeland Security, 2012), many students 
continue to travel from around the world to pursue a university education in the United States. In data obtained from the Institute of International Education's (2015) website for the 2012/2013 academic year, the United States recognized 819,644 international students studying at U.S. colleges and universities. In addition, the population of international students attending institutions of higher learning in the U.S. grew by $7 \%$ over the prior year and is currently at a record high (International Educational Exchange, 2013).

Despite their eagerness to study in the U.S., international students are faced with several obstacles upon arrival. Primarily these obstacles include language barriers, loneliness and homesickness, identity issues, changes in eating habits and other gastronomic adjustments, and financial setbacks (such as tuition, the cost of living, and the high cost of health insurance premiums). These difficulties take shape in a number of themes that will be discussed in this study.

The purpose of this qualitative study was to identify key aspects of the experiences, perceptions, and challenges of international students attending a university in a small town in the U.S.

Research questions:

1) What are the challenges international learners regularly confront when studying at a small town university;

2) Do these challenges differ or match the challenges of other international students; and, finally,

3) What are the reasons why students encounter such challenges?

\section{LITERATURE REVIEW}

\section{Challenges and Struggles of International Students}

Studies have shown that international students are lonely in their new environment because of not having familiar friends and social networks, of exposure to the new culture, and of being challenged by the linguistic and cultural nuances of language (McClure, 2007; Sawir, Marginson, Deumert, Nyland, \& Ramia 2008; Ip, Chui, \& Johnson, 2009). Sam (2001) highlighted the needs of social support and social networking for international students success. Having more international students in the university from the same social background might support their success. Sumer, Poyrzli, and 
Grahame (2008) emphasized good mental health and stated that a welcoming University and community can make a difference. Some Universities, by narrowly focusing on language or academic needs, miss other needs of international students (Tidwell \& Hanassab, 2007).

The literature has cited the issue of language barriers as one of the major challenges for non-English speaking international students in English speaking countries (Andrade, 2006; Tidwell \& Hanassab, 2007; Wright \& Schartner, 2013). English language proficiency matters for both academic success and social adjustment (Andrade, 2006). A very recent study from the United Kingdom (U.K.) showed that the international students "remained frustrated by a perceived 'threshold' barring successful interaction with English speakers, while reporting reluctance to take up available opportunities, independent of language proficiency and sociocultural adaptation" (Wright \& Schartner, 2013, p.113). Wright and Schartner (2013) challenged the linear models of adaptation of these students in the English-speaking world and called for assistance to international students in crossing the threshold to successful interaction. The language barrier not only alienated them, but, also, deprived them from social engagement with professors, friends, and other university family (Yeh \& Inose, 2003).

Park and Son (2011) focused prominently on language difficulties and cultural challenges. Sawir (2005) noted that staff and students highlight language as a basis for concerns and difficulties in the educational setting. Often students lack confidence and comprehension with English and lectures given in English. Idioms, writing conventions, and interpretation of meanings also pose concerns (Sawir, 2005, p. 569).

Lack of confidence in conversation becomes extensive to some (Sawir, 2005). When a university focuses only on language, other vital aspects like direct or indirect racism or discrimination in the host community may get overlooked. Lee and Rice (2007) referred to the impact of discrimination that international students experience in a new country. In this study, Lee and Rice cited neo-racism, or "new racism," as a form of discrimination based on culture and national order. Lee and Rice (2007) posit that discrimination manifests as neoracism as well. This concept appeals to contemporary nationalist biases about human nature and common sense, therefore reifying the 
exclusion of international students from culturally elite groups. As Lee and Rice state, "Underlying neo-racism are notions of cultural or national superiority and an increasing rationale for marginalizing or assimilating groups in a globalizing world" (p. 389). Additionally, Lee and Rice (2007) reported that European, Canadian, or white students perceived the discrimination less than Asian, Latin American, Middle Eastern, and nonwhite students.

Language is not the only challenge for international students. Financial, cultural, and socialization-related challenges also have an adverse effect on them. It is equally important to understand the perception of different religious categories. Loneliness becomes a huge issue as well. Therefore, to provide a healthy social space, universities need to support socialization and make social connections that eventually will support international students in achieving what they dream to achieve in their new setting (Sherry, Thomas, \& Chui, 2010). Sherry, Thomas, and Chui (2010) highlighted and confirmed the international students' challenging experiences. Offering a broader understanding of the phenomenon, Sherry et al. recognized cultural adjustment, challenges related to the English language, monetary challenges, and lack of networking with and from a larger network of university friends.

Whether or not there are any other distinctive challenges in small university town settings is still a valid question to ask. Despite these and many other possible challenges, international students have a strong presence in many ways in American academia. One such challenge is related to the identity and "the recognition of multiple identities" of the international students.

To speak to this need, Tate (2012) purported that international education necessitates transcending the concept of nations, communities, and ethnic groups. However, this transcendence does not suppress "the particular cultural identities that mean so much to people and that, where they coexist harmoniously, contribute to the attractiveness of our world" (p. 209).

Tate's (2012) observation provided a bitter reality and asked for the acknowledgment of various identities and the rejection of the idea that everyone must feel that they have only one identity. The identity shift, fluctuation, and multiple identities can be the challenges at the heart of a cultural analysis of problems faced by international 
students. They might look for a better opportunity to foster multiple identities.

Yeh and Inose (2003) explicitly raised the issues of cultural barriers, academic and financial difficulties, interpersonal problems, racial discrimination, loss of social support, alienation and homesickness. An early study by Mallinckrodt and Leong (1992) concluded that cross-cultural differences in social interaction caused international students to fail to form close relationships with American students. As data from IIE (2013) showed, the majority of international students in the U.S. are from Asia. As such, it becomes important to understand the contextual cultural barriers too. The studies of Mori (2000) as well as Yeh and Inose (2003) revealed that Asian international students may have higher difficulties on interacting and attempting to make social connections and make friends in a Western culture which emphasizes individualism, assertiveness, and self-sufficiency over interdependence and relatedness. Some show the concerns about safety and travel and transportation related issues ( $\mathrm{Lu}, \mathrm{Fu}, \&$ Adler, 2014).

Sandhu and Asrabadi (1998) identified emotional pain such as feelings of powerlessness, marginality, inferiority, loneliness, and perceived alienation and discrimination prevalent among international students. In a study, Zhang and Goodson (2001) reported challenges international students faced as "social support, English language proficiency, region/country of origin, length of residence in the United States, acculturation, social interaction with Americans, selfefficacy, gender, and personality" (p. 139). In this study the researchers state that each of these factors can vary in the degree of difficulty they offer to international students. There seems to be insufficient studies that seek to determine how these challenges differ on the basis of the size of the university or the setting of the university being a small town.

\section{RESEARCH METHOD}

Qualitative research explores the meanings, concepts, definitions, characteristics, metaphors, symbols and description of things (Berg, 2001) which best serve to bring forward the voice of international students who attend universities in the U.S. The research questions of 
qualitative studies emphasize the social experiences of the participants of this study. The value-laden nature of such an inquiry allows for the researcher and subjects to consider a given set of experiences and perceptions and then to make meaning of the situational constraints that define the study (Denzin \& Lincoln, 2011). As such, a qualitative design allowed the voice and concerns of the participants to be brought forward.

\section{Participants}

International students enrolled in a university in a small town in the southern region of the U.S. participated in the study. The university enrollment population was approximately 13,000 students, of which 110 were international students. Online surveys were sent via email to all 110 international students. Twenty-eight international students responded to the initial questionnaire, which was $25 \%$ of the total international student population. Out of the 28 respondents six international students participated in the in-depth interviews.

The participants represented a wide variety of national and cultural backgrounds. Six international students from different parts of the world participated in the interview: a Chinese male student, a Pakistani female student, an Argentinian female, a Serbian female, a Nepalese male, and a male student from Nigeria comprised the interview participants and purposive sample. These individuals represented different and diverse lingual, social, religious, and cultural backgrounds. As students at the university, three were graduate students (one was enrolled in a Ph.D. program and two were students at the master's level). The remaining three students were undergraduates (a senior, a junior, and a freshman).

\section{Data Collection Procedure}

Initially, an online questionnaire was administered to a larger participant group (28 international students). Data was collected using the online survey software known as Survey Monkey. Subsequent to this, responses to the initial questionnaire were used to develop an indepth interview to a purposively selected group of participants (six of the original 28 students) to provide more in-depth details to the qualitative data collected from the survey. Interviews were conducted on campus at the participants' convenience and at different times. One 
of the researchers conducted all the interviews, which were a set of predetermined questions. A series of various probing questions were employed as follow up. The interviews were audio recorded with consent by using available software (italk) and the files were later downloaded to a secure computer for transcription purposes. Later the participants were asked to read the transcripts to confirm that their views were accurate, well documented, and not distorted.

\section{DATA ANALYSIS}

We conducted an analysis of qualitative data through axial coding. NVivo was used to determine the frequency of thematic words and as a means for organizing data. After analysis of the survey data, themes and findings were compared, triangulated with the in-depth interviews (with participant confirmation of the accuracy of the transcription), and then converged to interpret the findings. It is the analysis of this final process that is reported in this study.

Credibility and Trustworthiness. In this study we adhered to a social construction approach following a constructivist paradigm (Patton, 2002). Traditional positivist scientific views of validity, reliability, and generalizability did not apply. However, as Patton (1999) asserted, "The credibility issue for qualitative inquiry depends on three distinct but related inquiry elements" (p. 1190). Therefore, we employed this alternative set of criteria for judging the credibility of this study (Denzin \& Linclon, 2011). As Lincoln and Guba (1985) and others (eg. Creswell, 2009; Denzin \& Linclon, 2011; Patton, 2002; Silverman, \& Marvasti, 2008) have suggested, qualitative approaches use accepted alternatives to validation.

Researchers sought to empower a small minority population by providing space for their authentic voice, and the interpretative analysis intentionally used the direct voices of the participants where possible. The size of the population of participants and the qualitative design did not lend itself to any type of generalizability. Participants in the in-depth interviews represented an array of cultures as well as different academic levels, degrees of maturity, and socio-cultural backgrounds. Their responses created a possibility of dialogue within the university, demonstrated respect to individual viewpoints, and 
attempted to do justice to the integrity of unique cases by giving equal voices to all the participants without generalizing their views. In addition, the team of researchers was compiled of two individuals from the U.S. and two individuals representing international heritage. This helped to provide a fair cultural critique of the interpretations.

We employed multiple interviews through survey and questionnaire, considered various perspectives both within the research team and from the perspectives of the participants, carefully analyzed all data collected in a fair and just manner, and endeavored, in their respect for the "value of qualitative inquiry," to provide richness and depth to the study. Additionally, researchers acknowledged the subjectivity of the research, and through thick description, a naturalistic methodology for data collection, and member checking, attempted to establish trustworthiness. By doing so, the researchers gave due "attention to issues of validity, reliability, and triangulation" (Patton, 1999).

The limitations to this study included a small sample size, the inclusion of only one type of data collected from questionnaires, and the inability to interview the participants in their mother tongue. Due to this final limitation, there exists the possibility that valuable information may have been lost in translation.

\section{RESULTS}

The participants in this study were international students attending a university in a small town in the southern/southwestern region of U.S. Originally, a survey was sent out to the entire international student population of 110 students via email. This list serve was obtained through the university's Office of International Students. There were twenty-eight students who attempted the survey, twenty-three of whom completed it entirely. In an effort to enhance understanding of key aspects relating to the problems and perceptions of international students, open-ended, follow-up interview questions served to further investigate their lived experiences. After an examination of these initial responses, the researchers decided on the themes that emerged from the responses provided. From these data, in-depth interviews were conducted with a purposeful sample of six of the original participants. Based on an analysis of participant responses, five 
primary themes emerged, themes that related to situational constraints and six subsequent themes concerned with specific types of socioeconomic and cultural challenges. The themes that emerged are summarized in Table 1.

Table 1: Situational Constraints and Socio- Economic/Cultural Challenges

\begin{tabular}{ll}
\hline Situational Constraints & The City \\
& The People \\
& The Opportunities \\
& The Plans and Successes \\
Socio-Economic/Cultural & Language \\
Challenges & Jobs and Finances \\
& Transportation \\
& Adjustment and Cultural Assimilation \\
& Cultural and Religious Encounters \\
& Double Identities \\
\hline
\end{tabular}

\section{Experiences and Challenges}

In the sections that follow, the qualitative themes that emerged from the textual data analysis are discussed. It is important to note that the quotes that are used are direct quotations and excerpts from the transcriptions of the qualitative interviews. We do not attempt to clarify the participants' messages or correct the participants' grammar. In essence, the technical and nontraditional manner in which the English language is used serves as evidence itself of the struggles that international students face.

The themes of experience manifest in the following headings: the city, the people, the opportunities, the plans, and the challenges. The topic of challenges is further analyzed in a series of subheadings: language, jobs and finances, transportation, adjustments and cultural assimilation, cultural and religious encounters, and double identities.

The city. The participants demonstrated both positive and not so positive reflections about the city. They revealed that the reputation of the university was a critical factor for them attending the university. However, they were troubled by the small town context of the city. 
This dichotomy produced interesting data although it was difficult to infer general themes as a result of the varying responses.

The male participant who was from China was planning to continue graduate school and liked the city since he personally preferred to live in a small city. He was from Beijing, China, one of the biggest cities in the world. He stated, "The population of Beijing is more than 20 million people. I personally like the quiet places. Here you know everyone."

However, the student from south Asia who expressed multiple concerns about the cultural experiences of a small town would choose a bigger city. She would prefer a city with an airport and more choices in regard to eating and entertainment too. The European student's view matched that of the south Asian participant. She said,

The difference will be the name of the city. This city nobody knows. If you have a degree from big city university people easily know where are you from. But universities like this are friendlier. Classes are small and one to one communication is there. Professors concentrate on the needs students.

The Chinese participant defended his preference for a small city with this statement: "For me it is the personal character. Some people do not like to talk. It is pretty common for some people to come here and they just do not talk." He further added, "Small cities force you to meet people of dominant culture, or mainstream culture." Additionally, he reflected that bigger cities might have their own limitations, stating, "Probably in bigger cities Chinese or Koreans or Japanese do not learn English because they have small pockets of their own people to talk to."

The South American participant was critical about the city and the university. "There are not many courses I cannot [can] take here. It is not the perfect for my $\mathrm{PhD}$. I noticed after coming here. They do not have the courses I want. I would have gone to other places like big cities," she said. However, the student from Africa came to the city or the university and knew that the university and city were not big names but that was okay for his area of study. He explained: "This school was not the school of choice for me. I applied to many schools but I got accepted here. I found out that the program was recognized 
by the petroleum related organization. I wanted to study petroleum geology."

The people. Analyzing the data revealed different factors that limited international students having contact with people. However, functions of the university's international program created opportunities to meet local people and face the experiences of the local culture. Many participants expressed that they had attended multiple social events in which they were able to meet people. This was not a response that all respondents shared however. Those who attended social events had positive experiences in doing so, while, once again, others shared a more critical perspective about the social experiences in a small town.

The South American participant was highly appreciative of the hospitality of the local people and culture, especially noting the willingness of people to help. She reflected: "The people here are kind with me. People here are helpful. In the beginning, I went to other schools. In my place if you missed, people say I do not know." She claimed to have received help all the time. She pointed out the differing culture of the people: "It is different, but it is good. All is formal here. That is different. They follow time. I like it. Many people do not like it. But I like it."

The participant from South Asia labeled her experience with people in a different manner, but still noting the theme of willingness to help. She found that people in the small town and university were very much helpful. She stated: "I went around the big cities like New York City, Miami etc. In big cities they do not have time for you. I mean for helping you. But here though they do not have time they make time for you."

The participant from a small country of Europe was critical about the people: "When I talk about the name of my country, nobody knows about. They always say the names of others like surrounding countries or places. That is annoying you know!" However, the participant from a small South Asian country was grateful to the people that they know where the country was. In fact they knew a lot about her country. They were curious to know about it. This surprised her because when she spoke to her family in her home country the knowledge was not reciprocated. In fact, she referred to talking about 
this small town with her family, saying, "I mean it is the town, my father cannot pronounce the name. He says the town that you have gone to." Still, the people of this town knew a lot about her country.

The opportunities. The participants were quite happy about the opportunities they were afforded through the international program office of the university. The participant from Africa made friends from different countries like South Korea, Pakistan, Saudi Arabia and many other countries. He had confidence that he would be able to make some American friends soon. "Probably I will make American friends once I go to Masters' classes. I am selective too. I want to know them before I call them friends. The program which I have completed now has only international students," he said.

The European participant agreed and expressed that "being international helps." She added, "Having an accent helps you. People come to you and talk to you." She explained the curiousness of people of this particular state and explained, "Especially here in [State]. [State] is like a different country. I have travelled to different big cities. I know how it looks in other places like California, Colorado, and others. For me, [State] is the most welcoming state."

The South Asian participant was extremely positive: "The job of International office is amazing." However, the African student was not quite as happy, citing the reason as not getting specific support for finding an on campus job. He perceived that the international office did not have the specific plans, guidance, or orientation to help international students find a job.

The plans and successes. All the participants were positive about the professional success their university experience would provide for them. While some revealed a desire to work in America, others wanted to return to their home. The Chinese participant said: "I think this university has prepared me for the job. I do not want to be American but want to be an American green card holder. I want to work in a Chinese company staying here." But he also compared the earning potential of staying or returning home, relating, "In China you can make more money than here."

The African participant was focused on self-development. "I do believe in self-development. Therefore, I do not believe that the 
university does everything," he explained. The participant from Europe provided a similar response to that of the participant from Africa. She stated: "I do not think school teaches you how to do the job ... you have to practice. School makes you prepared to think, and you have to do the rest of the practice yourself."

Nobody was as optimistic as the participant from South Asia. She emphasized, "In these four months I feel that I started to share my feelings easily. We noticed that we are good on communicating in English. Our confidence has been heightened. Coming to America is the highest point." However, the participant from South America was neutral. She was planning to return home soon after graduation. She noted, "There are many projects. I am working for my projects. I have personal projects. I need a personal project to do. . . . I will go back and work for my own country." She felt a strong sense of hope for success when returning home.

The challenges. When participants shared their challenges, several social, cultural, and economic themes began to emerge. The challenges they revealed were primarily related to six particular themes. These themes were language, transportation, finances, adjustments, socio-cultural adaptation, and other challenges unique to the participants. Although the researcher was neutral in regard to the religious aspect of the culture of the city and the university, a lot of participants connected religion and its role in their challenges during the interview. The challenges are discussed in a thematic manner in the sections that follow.

Language. English was a challenge for everyone. Among them, the South Asian participant said that her English fluency was adequate enough. However, she also highlighted that her friends helped her to improve a lot during the period of time she has been in the United States. The African participant focused on the difference between his English accent and the accents of the city, especially the local culture. The Chinese participant pointed out the whole notion of language as a stretching experience. He added how his teaching assistant position supported him in catching up with some aspects of English, especially with accents. The participants pointed out several encounters related to language. The South American participant said, 
"The language is an all day challenge for me outside the university. Inside the campus people try to understand you. But outside the campus, no. That limits me to go out. I cannot express my feelings."

The participant from Europe revealed a pedagogical challenge associated with language. She reflected:

Since my English is not perfect, I came to school with an imperfect English accent. I had to learn a lot of new words. I had to translate those words to our native language. I learn a new word but teacher changes that word to trick you. I do not know the meaning of that word and be in trouble. It was like double hard, I have to study double than everyone else to make same grades like others.

However, she was able to turn her weakness into a strength. She said, "I am white and look like other American white girls. I had to go in front and start conversations with the professors so that they notice me as an international student and help to meet my needs." She also revealed that the first two months of her American experience were very stressful because of her inability to communicate in English.

Jobs and finances. Except for the Chinese participant, others did not have any source of income in America. Obtaining a job became another central part of their narratives. They repeatedly expressed the struggles of getting an on-campus job. They were either uninformed about the process or were not confident that they could get a job. They shared the lack of network, references, or relevant experiences they felt they needed in order to get a job.

The Chinese student worked as a research assistant for some time and as a teaching assistant for the rest. He said that the teaching assistant job was more rewarding in regard to improving his knowledge and language skills. He explained: "They do not like to listen to our Chenglish [Chinese-English]. They get troubled."

The African participant, who was in a Masters' program, was worried about his financial status. He reasoned: "I do not have any family or relatives here. I stay off campus. It is totally different from the country where I came." He further elaborated the costs including 
the money he had to pay to attend school. He shared: "Meeting up with the phone bills and the rent is not easy. Food is not that hard. I spent like $\$ 100$ per month which is very ok for me." He was looking for an on campus job. "If I have a job or I can work, it would be good. I am hopeful and I am working for it. But there is not specific guidance for us," he said. The participants revealed that the university has general procedures for every student seeking a job. New international students were not sure how to apply and what the criteria were. The European participant focused on self-initiative for finding a job or developing herself for the job. The Chinese student's response was very much aligned with this notion. He emphasized the need of English language competency to get a job. He said: "I wanted to live with American students so that I can learn English. I think it is important to get the job."

Transportation. The transportation was a unique challenge that was directly related to the city of this study. There was not a dependable public transportation system available, an issue that was echoed by several participants. The participants revealed that even though the university does have a transportation system, it does not adequately meet the needs of individual international students. They also highlighted the complications of getting a driver's license and being accustomed to driving a car. Owning a car was a huge investment for them, which many of them felt they were unable to afford.

"Oh, the transportation is the big issue. I stay close to Campus. I cannot go to Wal-Mart. It is far. I go around to Kroger, CVS. I walk all the time," the African participant said. The South Asian participant shared an experience of walking up to Wal-Mart when she came to city for the first time. Later on they found somebody to give them a ride. Though the European participant drove her own car, she said that she had a number of friends that did not have a car and they had problems. She also revealed that in Europe they had public transportation even in small cities. She added: "In many places here you do not have a car means you do not have mobility. You even cannot go to store." This was the reality faced by the African participant who only traveled around the campus by walking. The Chinese participant felt the university transportation was 
adequate, but only because he rarely left campus. He revealed that not being allowed to work outside of the campus was more challenging. He said, "They hire only American citizens or legal immigrants. It is illegal to work outside the campus." Aligning with other participants, the South American participant said, "Transportation is a huge issue. I cannot buy a car here. It is difficult to move. However, I have a bike." The challenge of transportation was felt by many of the participants and it emerged as unique challenge due to the size of the city and the lack of a public transportation system.

Adjustment and cultural assimilation. Networking, social and cultural participation, and other areas of the participant's experiences were viewed as opportunities and challenges simultaneously. The South Asian participant shared her dorm with other American friends. She informed the researchers that her roommate was from a big city. It was a big contradiction from what she was accustomed to in her home. In her home she had her private restroom, and private space. Sharing restrooms was quite a challenge for her. "I had my personal room, and my own attached place. Here if you need to go to the restroom, then you come out of bed, out of your room, and to the hallway. There are those cubicles for the restrooms," she explained.

The African participant revealed that he feels lonely sometimes. He said: "I do not want to disturb others." The South American participant who stayed alone in an apartment however took it differently saying: "I was very independent, so I never feel lonely. However, when I am so tired, I question myself, what I am doing here? Where am I? But I make good grades. I am back to work again."

The European participant considered herself half European and half American. She added: "When I go to my country I still carry the typical boots from here. My language has changed. People at home get surprised hearing me. It is disappointing for me. They think I am somewhere on the top." She noted that her family thinks she has changed due to being in America. She further elaborated: "They think like head in the cloud. I do not want to be that one." She wanted to carry the values of her family. She also was cautious to state that "here people want me to change my faith which I do not like." 
Cultural and religious encounters. For Christians, there was not a problem in practicing their religion. They attended the church service and felt no discrimination or pressure due to their religion. The participant from Africa said: "I am a Catholic. I go to the Catholic Church here. No problem for it." The participant from South Asia who identified herself as a strong believer of Islam shared her encounter quite clearly:

It was so surprising to me that people are so religious here on their religion. I had an understanding that people in America are not that close to their religion. People asked me to come to their bible study. I felt like people call me to come to their bible study is something. As a Muslim, in our ceremonies we do not ask foreigner or anybody who is from other religion come and attend those things. But these people did, and I felt amazing. One of my friends gifted me a Bible. In our talks I understood that she knows Islam. I do not mean details. But she knew it, the teaching. They are strong Christian just like I am a Muslim, but they are being open-minded. I knew a bit about Christianity before. I started to learn about the Christianity more, but I am sticking to my religion.

The participant from Europe also explicitly shared that: "It was an experience. I was definitely in a different culture. [State], United States is different from my home country. In my home country there is no diversity. We all are orthodox Christians, and all white." Elaborating the cultural differences she critically added: "I feel that America is connected through religion. From my prospective they overdo religion. I love God. I feel here they fake a lot. Every time I visit their religious place, I feel a pressure to officially join their institution."

Double identities. Some of the participants raised the questions of identity. They either were dealing with the double identities, or multiple identities, they felt were created as the result of being international students. The participant from China, who was thinking of changing his field of study to advanced psychology, revealed that in coming to America he found many foreign students 
have problems related to their identities and notion of self. This led him to have an interest in pursuing psychology and eventually becoming an international consultant. However, he was not certain, and hesitant to pursue this dream.

Similarly the student from South America shared in questioning her identity. She asked herself, "What I am doing here? Where am I?" The participant from Africa said, "I feel loneliness sometimes." The participant from one of the small countries in Europe proudly shared that she does not have a problem staying with family until she finishes her college degree. She said, "I stay with my family. I do not have problem with living. As soon as I finish school I can find a job and find my own place. I do not want to be dependent forever." However she revealed her double identity of being European and American. She said that she would carry her religion and family values from her home country and take her work ethic from America with her as she continued her life after college. She elaborated, "In my home country, system is corrupted. Here if you work you bring money home. There, you cannot say that."

The participant from Europe presented an issue of friendship and linked it to the double identities she carries. "A lot of people are jealous. They say, 'Oh you are from Europe, blah blah blah.' Retaining friendships is a challenge for me here. Oh, I could never make a really good female friend here in America," she explained. She felt a strong sense that many of her acquaintances in America were not authentic. This caused a significant degree of confusion for her and caused her to question and distrust not only her own identity but also that of others.

\section{DISCUSSION AND CONCLUSIONS}

This study has attempted to contribute to what is known about this phenomenon. Much of what exists in the current literature was supported here. For example, language and academic challenges existed and emerged as real issues of difficulty for the participants.

However, there were several aspects of this study that were unique and deserve the attention of universities interested in better serving their international student population, especially universities that reside in small towns or regional settings. First, the notion of 
transportation was an essential element of the challenges that the participants of this study expressed. Small cities that lack the infrastructure of public transit and other viable means of movement inhibited the participants of this study. This has important implications for universities in small towns in connecting with and understanding their international student populations. These universities might seek to address this problem through innovative ways of providing transportation for international students.

Transportation around the small towns or even to larger urban areas as ways for these international students to connect with their home culture could provide for unique and important traits of universities, thus increasing the educational experiences of their international students. An effort like this on the part of universities could also address some of the cultural and assimilation perceptions that were expressed by the participants of this study. This could also have the effect of further attracting future international students to universities of a similar demographic.

Another important theme that emerged and that was unique to this study is the impact of religion. Religion is a large component of many people's lives and culture. Many universities in small towns exist in social and cultural contexts that hold very strong and rigid religious beliefs. Addressing the varying religious and spiritual needs of international students in these small towns emerges as a concern of many learners. Creating universal environments and democratic spaces through the university that provide international students a place for religious expression and activity could have a huge impact on the attractiveness of these universities in small towns. If establishing such spaces is a concern for public state universities, we recommend democratically developing programs and centers that foster awareness of religious diversity.

In summation, as the Chinese participant noted, the challenges of international students change with time. He said that as soon as you come here, the initial challenge is the language. During that time you do not communicate, or communicate correctly with your friends, or your American friends. Meanwhile, as time passes, then the challenge becomes the shock of the idiosyncrasies of culture. After the initial cultural shock, then the challenges shift to academic issues. Different educational programs and professors embrace varying views on 
assignments and workload, but, regardless, one must take on a lot of readings and write numerous papers that add to international students' academic challenges. Financial, social, and religious challenges persist throughout the international student experience.

The essential purpose of this study was to further what was known about the challenges international students face. Higher education is faced with the reality of an increasing population of international students. With this study's focus on the context of universities in small towns, the data could be significant for universities with similar demographics and utilized to positively impact the educational experiences of international students. Any discussion surrounding the challenges of international students can only benefit the universities in addressing these issues, ultimately helping these establishments of higher learning in the education of all of students.

\section{RECOMMENDATIONS FOR RESEARCH}

Recommendations concluded from this study are two-fold, focusing on research and on policy. Given the scope of this study, the primary recommendation calls for efforts to extend the field of study to various universities located in small-town venues throughout the U.S. Such an effort would allow educators to derive commonalities in struggles that their international students face and work to enact policies and programs to better serve those students. In addition, a recommendation is also made to conduct studies to generalize challenges that international students confront, such as quantitative and mixed-methods studies.

Based on the finding of this study, it is recommended that universities and other institutions of higher learning in small towns take up innovative efforts to provide international students supports and systems that enhance their experience. Administrators and policymakers can give attention to programs that focus on providing international students with opportunities for social connections and means to make those connections, for example those enhanced transportation efforts on campus and in town. 


\section{IMPLICATIONS FOR PRACTICE}

Universities across the United States can utilize this study to further assist them in providing adequate accommodations for international students as well as in recruiting global students based on what the universities have to offer. For example, students from countries in which English is not their first language immediately face an uphill battle upon arrival to the United States. However, they are required to complete their degrees in English within the allotted time frame as stipulated by their student visa despite these challenges.

What can colleges and universities do to continue to motivate international students to confront this challenge? Concerning outreach and retention it is important to ask, what prompts some students to be successful in the face of adversity while others become frustrated and even fail? Also, in conclusion, many questions will need to be explored to determine factors of successes and failures of international students in a small town university and how these factors can be measured.

\section{REFERENCES}

Andrade, M.S. (2006). International students in English-speaking universities: Adjustment factors. Journal of Research in International Education, 5(2), 131-154.

Australian Government. (2014). Why study in Australia? Retrieved from http://www.studyinaustralia.gov.au/global/why-australia.

Baumann, S. (2012). Educating international students. Nursing Science Quarterly, 25(1), 97-98.

Berg, B. L. (2001). Qualitative research methods for the social sciences (Fourth edition). Boston, MA: Allyn \& Bacon.

Collins, K.M., Onwuegbuzie, A.J., \& Sutton, I.L. (2006). A model incorporating the rationale and purpose for conducting mixedmethods research in special education and beyond. Learning Disabilities: A Contemporary Journal, 4(1), 67-100.

Creswell, J. W. (2009). Research design: Qualitative, quantitative, and mixed methods approaches. Thousand Oaks, CA: Sage.

Denzin, N. K., \& Lincoln, Y. S. (2000). Introduction: The discipline and practice of qualitative research. In N. K. Denzin and Y. S. 
Lincoln (Eds.), The SAGE Handbook of Qualitative Research (pp. 1-19). Thousand Oaks, CA: Sage.

Denzin, N. K., \& Lincoln, Y. S. (Eds.). (2011). The SAGE handbook of qualitative research (Fourth edition). Thousand Oaks, CA: Sage.

Department of Homeland Security. (2012, May 23). Students and exchange visitors. Retrieved from www.uscis.gov/workingunited-states/students-and-exchange-visitors

Hazelkorn, E. (2011). Globalisation and the reputation race. In E. Hazelkorn (Ed.), Globalization and the reputation race in rankings and the reshaping of higher education: The battle for eorld wide excellence (pp. 6-38). Dublin: Palgrave MacMillan.

International Educational Exchange (IEE). (2013). Open doors report. Retrieved from www.iie.org/Research-and-Publications/OpenDoors/Data/International-Students/Infographic

Institute of International Education (IIE). (2013). International students by academic level, 2011/12-2012/13. Open Doors Report on International Educational Exchange. Retrieved from www.iie.org/opendoors

Ip, D., Chui, E., \& Johnson, H. (2009). Learning experiences and outcomes of culturally and linguistically diverse students at the University of Queensland: A preliminary study. Brisbane: The University of Queensland

Lee, J., \& Rice, C. (2007). Welcome to America? International student perceptions of discrimination. Higher Education, 53, 381-409.

Levin, R. (2008). The American university and the global agenda April 16, 2008. Retrieved from www.fpa.org

Lu, Y., Fu, X., \& Adler, H. (2014). Travel safety concerns: Feedback from international students in the USA. International Journal of Tourism Anthropology, 3(3), 211-226.

Mallinckrodt, B., \& Leong, F.T.L. (1992). International graduate students, stress, and social support. Journal of College Student Development, 33, 71-78.

McClure, J.W. (2007). International graduates' cross-cultural adjustment: Experiences, coping strategies, and suggested programmatic responses. Teaching in Higher Education, 12(2), 199-217. 
Mori, S. (2000). Addressing the mental health concerns of international students. Journal of Counseling \& Development, $78,137-144$.

NAFSA. (2014). The international student economic value tool. NAFSA: Association of International Educators. Retrieved from www.nafsa.org

Park, S.S., \& Son, J.B. (2011). Language difficulties and cultural challenges of international students in an Australian university preparation program. In A. Dashwood (Ed.), Language, culture and social connectedness (pp. 35-55). Newcastle, UK: Cambridge Scholars.

Patton, M. Q. (2002). Qualitative research \& evaluation methods (3rd ed.). Thousand Oaks, CA: Sage.

Sam, D.L. (2001). Satisfaction with life among international students: An exploratory study. Social Indicators Research, 53, 315337.

Sandhu, D.S., \& Asrabadi, B.R. (1998). An acculturative stress scale for international students: A practical approach to stress management. In C.P. Zalaquett \& R.J. Wood (Eds.), Evaluating stress: A book of resources, Vol. 2 (pp. 1-33). Lanham, MD: Scarecrow.

Sawir, E. (2005). Language difficulties of international students in Australia: The effects of prior learning experience. International Education Journal, 6(5), 567-580.

Sawir, E., Marginson, S., Deumert, A., Nyland, C., \& Ramia, G. (2008). Loneliness and international students: An Australian study. Journal of Studies in International Education, 12(2), 148-180.

Sherry, M., Thomas, P., \& Chui, W.H. (2010). International students: A vulnerable student population. Higher Education, 60(1), 3346.

Sumer, S., Poyrazli, S., \& Grahame, K. (2008). Predictors of depression and anxiety among international students. Journal of Counseling and Development, 86, 429 - 437.

Tate, N. (2012). Challenges and pitfalls facing international education in a post-international world. Journal of Research in International Education, 11(3), 205-217. 
Tidwell, R., \& Hanassab, S. (2007). New challenges for professional counselors: The higher education international student population. Counseling Psychology Quarterly, 20(4), 313324.

Wright, C., \& Schartner, A. (2013). 'I can't ...I won't?' International students at the threshold of social interaction. Journal of Research in International Education, 12(2), 113-128.

Yeh, C.J., \& Inose, M. (2003). International students' reported English fluency, social support satisfaction, and social connectedness as predictors of acculturative stress. Counseling Psychology Quarterly, 16(1), 15-28.

Zhang, J., \& Goodson, P. (2011). Predictors of international students' psychosocial adjustment to life in the United States: A systematic review. International Journal of Intercultural Relations, 35(2), 139-162.

Silverman, D., \& Marvasti, A. (2008). Doing qualitative research: A comprehensive guide. Thousand Oaks, CA: Sage.

CHETANATH GAUTAM, Ed.D., serves as a post-doctoral research associate at Stephen F. Austin State University. He also holds the Masters of Philosophy in Educational Leadership from Kathmandu University and the Ed.D. from Stephen F. Austin State University. He was named a UCEA Barbara Jackson Scholar in 2013. His research interests include global educational studies, educational leadership for social justice and democracy, and educational experiences of international students as well as diverse groups of learners. Email: cngautam@gmail.com

CHARLES L. LOWERY, Ed.D., is an assistant professor in Educational Studies at Ohio University. He holds the M.Ed. in Educational Administration from Stephen F. Austin State University and an M.S. in Instructional Design and Technology from Walden University. He earned his Ed.D. in Educational Leadership from Stephen F. Austin State University. His research interests include educational leadership for social justice as well as perceptions and challenges of marginalized individuals in educational settings. Email: loweryc@ohio.edu 
CHANCE D. MAYS, Ed.D., currently serves as the High School Principal at Mount Enterprise High School in East Texas. He holds the Ed.D. from Stephen F. Austin State University. His main research interests include educational philosophy, including the role of democracy in education and society, with an emphasis on the role experiences play in education, as well as moral philosophy, virtue ethics, and their relevance to practicing educational leaders in modern society. Email: chancemays11@gmail.com

DAYAN G. DURRANT, has been a student in the Educational Leadership doctoral program at Stephen F. Austin State University for the past three years. He currently serves a Career and Technology Education educator and researcher. His research interests include not only his professional field but also school district consolidation as well as politics and policy and it impact on social justice. Email: garrethdurrant@hotmail.com 